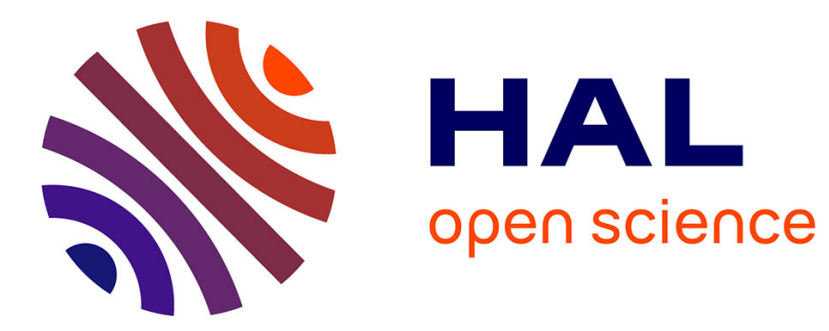

\title{
Predicting Mixture Coadsorption in Soft Porous Crystals: Experimental and Theoretical Study of $\mathrm{CO} 2 / \mathrm{CH} 4$ in MIL-53(Al)
}

Aurélie U. Ortiz, Anne Springuel-Huet, François-Xavier Coudert, Alain H. Fuchs, Anne Boutin

\section{To cite this version:}

Aurélie U. Ortiz, Anne Springuel-Huet, François-Xavier Coudert, Alain H. Fuchs, Anne Boutin. Predicting Mixture Coadsorption in Soft Porous Crystals: Experimental and Theoretical Study of CO2/CH4 in MIL-53(Al). Langmuir, 2012, 28 (1), pp.494-498. 10.1021/la203925y • hal-01468499

\author{
HAL Id: hal-01468499 \\ https://hal.science/hal-01468499
}

Submitted on 2 May 2019

HAL is a multi-disciplinary open access archive for the deposit and dissemination of scientific research documents, whether they are published or not. The documents may come from teaching and research institutions in France or abroad, or from public or private research centers.
L'archive ouverte pluridisciplinaire HAL, est destinée au dépôt et à la diffusion de documents scientifiques de niveau recherche, publiés ou non, émanant des établissements d'enseignement et de recherche français ou étrangers, des laboratoires publics ou privés. 


\title{
Predicting mixture coadsorption in Soft Porous Crystals: Experimental and theoretical study of $\mathrm{CO}_{2} / \mathrm{CH}_{4}$ in MIL-53(Al)
}

\author{
Aurélie U. Ortiz, ${ }^{1}$ Marie-Anne Springuel-Huet, ${ }^{2}$ François-Xavier Coudert, ${ }^{1, *}$ Alain H. Fuchs, ${ }^{1}$ Anne Boutin ${ }^{3}$ \\ ${ }^{1}$ CNRS and Chimie ParisTech, LECIME (UMR 7575), 11 rue Pierre et Marie Curie, 75005 Paris, France. \\ ${ }^{2}$ Laboratoire de Chimie de la Matière Condensée de Paris, Univ. Pierre et Marie Curie, 75252 Paris Cedex 05, France. \\ ${ }^{3}$ Chemistry Department, École Normale Supérieure, UMR 8640 CNRS-ENS-UPMC, 24 rue Lhomond, 75005 Paris, France.
}

Keywords: metal-organic frameworks, adsorption, structural transition, breathing, thermodynamics, gas mixture adsorption.

\begin{abstract}
We present a synergistic experimental and theoretical study of $\mathrm{CO}_{2} / \mathrm{CH}_{4}$ mixture coadsorption in breathing metal-organic framework MIL-53(Al). Mixture adsorption experiments were performed and their results were analyzed by comparing them to predictions made from pure-component adsorption data using the Osmotic Framework Adsorption Solution Theory (OFAST). The analytical model, fully validated for the first time, was then used to predict coadsorption properties as a function of temperature, pressure and mixture composition. The phase diagrams obtained show a surprising nonmonotonic behavior.
\end{abstract}

Porous metal-organic frameworks (MOF) are a topical class of materials that display an extremely large range of crystal structures and host-guest properties, potentially giving them a major impact in many areas of science and technology. ${ }^{1,2,3}$ In particular, they have potential applications in the fields of heterogeneous catalysis ${ }^{4}$ and adsorptive separation of fluids. ${ }^{5,6}$ Much attention has recently been focused on a fascinating subclass of metal-organic frameworks that behave in a remarkable stimuli-responsive fashion. These Soft Porous Crystals ${ }^{7}$ (SPC) feature dynamic crystalline frameworks displaying reversible, large-amplitude structural deformations under external physical constraints such as temperature, ${ }^{8}$ mechanical pressure ${ }^{9}$ or gas exposure. ${ }^{10,11}$ A number of these materials have been proposed as candidates for processes of adsorption separation of mixtures containing $\mathrm{CO}_{2}$, a crucial step in the capture and sequestration of carbon dioxide from flue gas. These include members of the MIL-53 materials family, which can oscillate between two metastable structures (a large-pore form, lp, and a narrow-pore form, np) upon adsorption, a phenomenon called breathing.

While many authors have stated that soft porous crystals are good candidates for adsorptive gas separation, such predictions are usually based solely on looking at their pure-component adsorption properties. Direct measurements of gas mixture adsorption selectivities are scarce, ${ }^{12,13,14,15}$ and the larger parameter space involved in such studies is hard to fully explore experimentally. The Osmotic Framework Adsorption Solution Theory (OFAST) was recently proposed as an attempt to fill this void and allows theoretical prediction of mixture coadsorption in flexible nanoporous materials, based on their pure-component adsorption properties alone. ${ }^{16} \mathrm{We}$ present here a combined experimental and theoretical study of the coadsorption phase diagram of a $\mathrm{CO}_{2} / \mathrm{CH}_{4}$ mixture in MIL-53(Al), investigating the evolution of the breathing as a function of temperature, pressure and mixture composition. The theoretical predictions are in good agreement with the experiments, thus validating the OFAST model for such simple gas mixtures.

Experimental methods. The sorption experiments of a mixture of carbon dioxide and methane were carried out at various temper- atures $(253,273,292$ and $323 \mathrm{~K}$ ) and pressures (ranging from 0.5 to 9.5 bars) using an "Intelligent Gravimetric Analyser" (IGA system) from Hiden Isochema. This instrument allows dynamic multicomponent gas sorption experiments in both pressure and flow control modes.

The MIL-53(Al) sample (about $36 \mathrm{mg}$, of the same origin as the one used in ref 17) was deposited in a mesh container suspended from a hook (constituting one part of the balance). The whole is placed in a stainless steel chamber of $1.8 \mathrm{~L}$. Prior to sorption measurements, the sample was activated at $423 \mathrm{~K}$ overnight under a helium flow.

The uptake-release isotherms were measured, at fixed temperature and total gas pressure, as a function of the gas composition which was varied step-by-step. The "uptake" branch corresponds to the increase of the molar fraction of carbon dioxide from 0 to $100 \%$, the "release" branch to the decrease of this ratio. A total gas flow of $100 \mathrm{cc} / \mathrm{min}$ was used for all the experiments. Typically, the measurement of an uptake-release isotherm takes 7 to $30 \mathrm{~h} .14$ to 35 data points were measured for each isotherm.

To perform the experiments at $253 \mathrm{~K}, 273 \mathrm{~K}$ and $323 \mathrm{~K}$, the chamber was placed in a thermostatic bath containing an ethylene/glycol mixture whose temperature was controlled with an accuracy of $0.5 \mathrm{~K}$.

Theoretical models. The coadsorption isotherms for the $\mathrm{CO}_{2} / \mathrm{CH}_{4}$ mixtures were calculated from pure-component data available from the literature ${ }^{17}$ using the Osmotic Framework Adsorbed Solution Theory (OFAST). ${ }^{16}$ This method couples the description of the adsorbed mixture as an ideal solution in each possible host structure (following the IAST prescriptions put forth by Myers and Prausnitz ${ }^{18}$ ), and the thermodynamic equations of the osmotic ensemble describing the equilibrium between guestloaded host structures. ${ }^{19}$

The osmotic ensemble $\left(N_{\text {host }}, \mu_{\mathrm{ads}}, \sigma, T\right)$ is the thermodynamic ensemble pertinent to the description of the adsorption of fluids (and fluid mixtures) into flexible porous frameworks. Its control 
parameters are the number of molecules of the framework, $N_{\text {host; }}$ the chemical potential of the fluids, $\mu_{\text {ads; }}$ the mechanical constraint exerted on the system, $\sigma$ (which in simple isotropic cases without external stress reduces to the total fluid pressure, $P$ ); and the temperature, $T$. In the case of most soft porous crystals, the flexibility displayed is due to multistability: the material may alternate between different preexisting metastable structures, the stability of which is influenced by guest loading. In this case, the osmotic subensemble can be used to describe the system in equilibrium between the host phases $k$, i.e. the volume $V$ of the system can only take a finite number of values $\left\{V_{k}\right\} .{ }^{20}$ For each host structure $k$, the subosmotic thermodynamic potential upon adsorption is given by:

$$
\Omega_{k}^{\mathrm{os}}(\mu, P, T)=F_{k}^{\mathrm{host}}(T)+P V_{k}-\int_{-\infty}^{\mu} N_{k}^{\mathrm{ads}}(T, \mu) \mathrm{d} \mu
$$

where $F_{k}^{\text {host }}(T)$ is the free energy of the guest-free phase $k$ of the material, and $N_{k}$ ads $(T, \mu)$ is the total quantity of all adsorbed species in host structure $k$. The former term can be calculated from purecomponent experimental data, ${ }^{21}$ while the latter is calculated using (or, to be more accurate, approximated by) ideal-solution equations using pure-component isotherms as their input. ${ }^{22}$

The OFAST method naturally extends to the analysis of temperature dependency provided that temperature-dependent purecomponent data is available. This can be achieved by fitting experimental data using well-behaved isotherm models and Arrhenian temperature dependencies, as done in the case of xenon adsorption in MIL-53(Al) by Boutin et al. ${ }^{23}$ In this work, we used the model parameters provided by a previous mixed experimental/theoretical adsorption study of $\mathrm{CO}_{2}$ and $\mathrm{CH}_{4}$ in MIL-53( $\left.\mathrm{Al}\right),{ }^{17}$ without any modification or readjustment.

Experimental isobars-isotherms at $273 \mathrm{~K}$. We report in Figures 1 and 2 the evolution of total adsorbed fluid mass, i.e. $m_{\mathrm{ads}}=$ $m_{\text {ads }}\left(\mathrm{CO}_{2}\right)+m_{\text {ads }}\left(\mathrm{CH}_{4}\right)$, measured in weight $\%$, as a function of mixture composition for the $\mathrm{CO}_{2} / \mathrm{CH}_{4}$ mixture in MIL-53(Al) at $273 \mathrm{~K}$ and various values of total gas pressure (from 0.5 to $9.5 \mathrm{bar}$ ). These measurements, performed with both $x\left(\mathrm{CO}_{2}\right)$ increasing from 0 to 1 , and then decreasing back to 0 , yield monotonic curves: the total adsorbed mass increases with $\mathrm{CO}_{2}$ composition for all measurements reported in this work, as a consequence of the much larger affinity of carbon dioxide than methane. Thus, we call the isobar-isotherm curves upon $\mathrm{CO}_{2}$ composition increase the uptake curves, and the curves obtained upon decreasing $\mathrm{CO}_{2}$ molar fraction (or increasing methane composition) the release curves. Among the eight isobars-isotherms measured at $273 \mathrm{~K}$, those at 2.75, 3.5 and 4 bar (Fig. 2) each feature two steps (the first one being very small at 4 bar). These steps are associated with hysteresis loops and are indicative of a breathing structural transition induced by the adsorption of the mixture. For pressures lower than 2.75 bar, a single transition is observed, while at high pressure $(P \geq$ 8 bar), no transition is seen. This demonstrates the complexity of the behavior of the flexible MIL-53(Al) upon mixture adsorption, as well as the difficulty of attributing these breathing transitions from isotherms without any addition structural evidence, e.g. from in-situ X-ray diffraction.

The data obtained for $x\left(\mathrm{CO}_{2}\right)=0$ or 1 from these coadsorption isotherms (i.e. pure methane or carbon dioxide) were compared to pure-component adsorption data previously published ${ }^{17}$ (Fig. S2). The agreement is very good over the entire pressure range, with slight differences inside the hysteresis loop for $\mathrm{CO}_{2}$. The amount adsorbed depends strongly on the history of the system. Thus, the amount adsorbed in a given set of thermodynamic conditions depends on whether it is measured as part of a pressure swipe at fixed $x$, or by varying $x$ at fixed pressure. In particular, we experimented with various treatments of our sample and found that the most reliable way to fully convert it completely into its $\mathrm{lp}$ form at room temperature is to "activate" it at high $\mathrm{CO}_{2}$ pressure (pure $\mathrm{CO}_{2}, 9.5$ bar, $273 \mathrm{~K}$ ) rather than under a vacuum. This is due to the fact that the large-pore form of MIL-53(Al) is more stabilized under $\mathrm{CO}_{2}$ adsorption at high pressure than in the evacuated sample. This is consistent with the fractions of $\mathrm{lp}$ and $\mathrm{np}$ phases measured by in-situ X-ray diffraction during $\mathrm{CO}_{2}$ adsorption and desorption by Serre et al. ${ }^{24}$ In particular, this can been seen by the difference in the points of the uptake and release branches in Fig. 2a, where the sample was exposed to pure $\mathrm{CO}_{2}$ at 5 bar (thus converting it fully into the lp phase) between the measurement of the uptake and release curves.

Pressure-composition phase diagrams - Comparing experiments and theory. To shed some light into the influence of mixture composition on the breathing of MIL-53, we plotted each step observed on the experimental isotherms at $273 \mathrm{~K}$ (Figs. 1 and 2) on a pressure-composition diagram. ${ }^{16}$ For each step, we considered that the composition of the transition at equilibrium must lie inside the hysteresis loop, and marked the two extremes of the loop as bracketing the transition. This experimental $(P, x)$ diagram is reported on Figure 3. In parallel, we calculated the theoretical diagram predicted by the OFAST method, ${ }^{16}$ using the adsorption parameters derived from experimental data in our previous work for pure-component $\mathrm{CO}_{2}$ and $\mathrm{CH}_{4}$ adsorption. ${ }^{17}$ This theoretical diagram, reported in blue on Fig. 3, is in excellent agreement with the experimental transition ranges (the magenta bars). While the OFAST method had previously been validated only on a limited set of coadsorption selectivities from dynamic breakthrough measurements on this system, ${ }^{12}$ the present experimental work provides a direct validation of this recent theoretical model on the full range of molar fraction, pressure and temperature (the latter will be detailed below).

The $(P, x)$ phase diagram fully explains the complex behavior of the system and the features of the isotherms in Fig. 1 and 2. These isotherms correspond to horizontal lines in the diagram. At low pressure, one transition is observed upon increase of $\mathrm{CO}_{2}$ mole fraction, going from the open form to the closed form $\left(\mathrm{CH}_{4}\right.$ does not induce breathing at this temperature). At intermediate pressure, two successive transitions are seen (lp-np-lp), as MIL-53 is open with both gases, but can be closed by a mixture of the two. At higher pressure, no breathing is observed anymore.

Some striking features of this pressure-composition diagram can be highlighted. Firstly, the evolution of the material's reopening pressure (the np-to-lp transition) with the $\mathrm{CO}_{2}$ molar fraction is nonmonotonic, unlike that of the lower-pressure lp-to-np breathing. This has the consequence that the reopening pressure for the material is, in a large range of composition, larger for the mixture than for the $\mathrm{CO}_{2}$ itself. In other words, mixing $\mathrm{CO}_{2}$ (which triggers breathing) with $\mathrm{CH}_{4}$ (which does not) increases the pressure domain of the breathing phenomenon. This feature, first predicted in our earlier theoretical work, ${ }^{16}$ is confirmed experimentally with this study. This is due to the fact that addition of $\mathrm{CH}_{4}$, which does not trigger breathing at this temperature but contributes to the increase in total gas pressure. A second notable feature is the relatively low value of the critical breathing composition, i.e. the minimum concentration at which breathing can be observed. Less than $5 \%$ of $\mathrm{CO}_{2}$ added to a flow of $\mathrm{CH}_{4}$ is enough to trigger the breathing of 
MIL-53(Al) under adsorption at pressures between 1.5 and 4 bars, while the material does not breathe with pure $\mathrm{CH}_{4}$ at this temperature. Indeed, because the affinity of $\mathrm{CO}_{2}$ for the framework is so much higher than that of $\mathrm{CH}_{4}$, it adsorbs preferentially, and even a small amount is sufficient for the breathing to take place. This has important practical consequences for the design of adsorptive gas separation processes using soft porous crystals, as it shows that traces of gases with a strong adsorption enthalpy can drastically modulate the structural transitions (gate opening or breathing) of flexible frameworks upon adsorption. In particular, we expect this behavior to be even stronger with more polar adsorbates, such as water and hydrogen sulfide.

Influence of temperature on the adsorption isotherms. In order to study the effect of temperature on mixture coadsorption, we measured uptake and release isobars-isotherms on the same system at 253, 292 and $323 \mathrm{~K}$, for a variety of pressures from 0.5 to 8 bar. These 16 isotherms are plotted in Figures S3 to S5. For each temperature, the pressure-composition phase diagram was calculated using the OFAST method, and the transitions observed experimentally were reported on top. All three diagrams are displayed on Figure 4. The overall agreement is good, especially considering that the theoretical OFAST diagrams are drawn solely from purecomponent data, without any reparametrization. Minor deviations from the experimental values are observed at low $\mathrm{CO}_{2}$ molar fraction, which we attribute to the large sensitivity of the OFAST equations to $x\left(\mathrm{CO}_{2}\right)$ in this domain, amplifying possible deviations of the adsorbed mixture from the Ideal Adsorbed Solution Theory.

The four $(P, x)$ phase diagrams, ranging from 253 to $323 \mathrm{~K}$, display a clear evolution of the breathing phenomenon with temperature. The lowest temperature, $253 \mathrm{~K}$, is very close to the maximal temperature for which $\mathrm{CH}_{4}$ can induce breathing, which is $245 \mathrm{~K}^{17}$ Consequently, the critical breathing composition of the mixture is close to 0: it takes minute amounts of $\mathrm{CO}_{2}$ to favor the narrow-pore structure and make the material breathe. Moreover, since the low temperature favors adsorption at lower pressure, the pressure span of the diagram is restricted to $0-8$ bar. By increasing temperature, we heighten the free energy difference between the lp and np phases, enhancing the stability of the lp phase $\left(S_{\mathrm{lp}}>S_{\mathrm{np}}\right)$ and making it harder for the adsorbates to trigger structural transitions. Thus, the critical composition increases with temperature, reaching $20 \%$ at $323 \mathrm{~K}$. In addition, the diagram sees a global shift to higher pressure, as Henry constants diminish with temperature. Thus, the peak in breathing pressure, at intermediate compositions, becomes less marked. Finally, it is seen that the hystereses between the two phases become more pronounced, with larger isotherm loops, which can also be linked to the larger free energy difference, and thus the larger free energy barriers, between the lp and np phases.

Exploration of the three-dimensional parameter space. The OFAST model being a fast, analytical method for the calculation of phase stability and mixture coadsorption, it allows to perform calculations in the entire $(T, P, x)$ parameter space. This is an important feature for the simulation and optimization of adsorption processes, as well as to guide the experimental exploration of the large multi-dimensional parameter space. In particular, it allows the optimization of operating parameters for designing adsorption separation columns and processes, e.g. by using equilibrium data as an input to simulations of adsorption column dynamics. Thus, phase diagrams of MIL-53( $\mathrm{Al}$ ) upon $\mathrm{CO}_{2} / \mathrm{CH}_{4}$ adsorption can be presented as three-dimensional objects, though those are difficult to visualize. We present on Figure 5 the evolution of the $(T, P)$ phase diagrams with mixture composition, which are cuts of the 3D diagram along constant-composition planes. We can thus see how the material breathes in the presence of various mixtures.

Plotted on the same scale, it appears that the domain of stability of the np phase is smaller for methane than for carbon dioxide, both in terms of pressure and temperature range. As it was already seen on the constant-temperature diagrams, the breathing pressure ranges extend for intermediate compositions to values larger than for the pure component; this effect is observed at all temperatures. Moreover, we can see that the role of the gases is not symmetric: the phase diagram is much more sensitive to the presence of a small fraction of $\mathrm{CO}_{2}$ in $\mathrm{CH}_{4}$ than it is for mixtures mostly composed of carbon dioxide. This sensitivity is particularly highlighted by the difference between the phase diagrams for pure methane and $20 \%$ $\mathrm{CO}_{2}$, which have very different extensions in terms of pressure ( 2 bar vs. 11 bar) and temperature $(245 \mathrm{~K}$ vs. $315 \mathrm{~K})$. We will direct further investigations into the influence of traces of polar gases in mixtures, as well as the limits of validity of the Ideal Adsorbed Solution Theory for such dissymmetric mixtures.

We performed a synergistic experimental and theoretical study of the adsorption of $\mathrm{CO}_{2} / \mathrm{CH}_{4}$ mixtures in the soft porous crystal MIL-53(Al), exploring the three-dimensional parameter space of pressure, temperature and mixture composition. We demonstrated an experimental methodology to construct $(P, x)$ phase diagrams for this breathing material, and showed that the OFAST method allows to analyze this data. This fully validated this analytical treatment of mixture adsorption. Furthermore, we predicted the flexibility of the material in the full $(P, T, x)$ parameter space. We highlighted the dissymmetry in the role of $\mathrm{CO}_{2}$ and $\mathrm{CH}_{4}$ in the mixture, and the very high sensitivity of the breathing pressures to the mole fraction of $\mathrm{CO}_{2}$ in almost-pure $\mathrm{CH}_{4}$. Finally, we showed that the shape of the $(P, T)$ phase diagram for MIL-53 upon gas adsorption is very generic, and valid for gas mixtures as well as pure components.

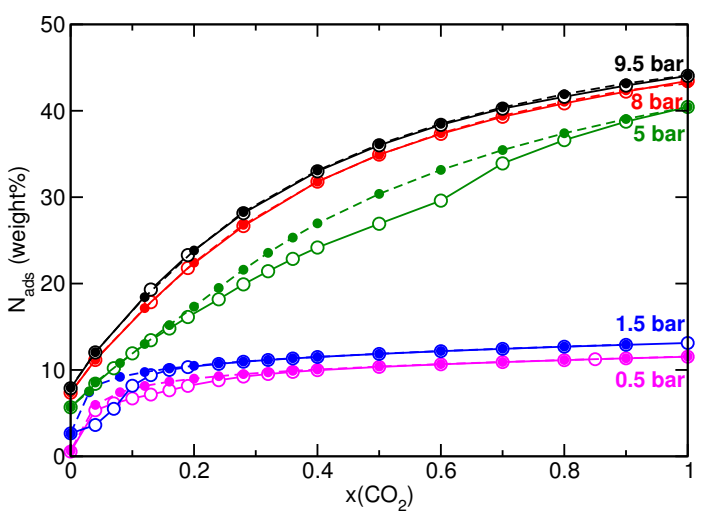

Figure 1. Experimental uptake and release isobars-isotherms of a mixture of $\mathrm{CO}_{2}$ and $\mathrm{CH}_{4}$ in MIL-53(Al), as a function $\mathrm{CO}_{2}$ molar fraction, at $273 \mathrm{~K}$. Each curve corresponds to a fixed value of total gas pressure, ranging from 0.5 to 9.5 bar. Open symbols correspond to increasing $\mathrm{CO}_{2}$ fraction ("uptake"), full symbols to decreasing ("release"). 

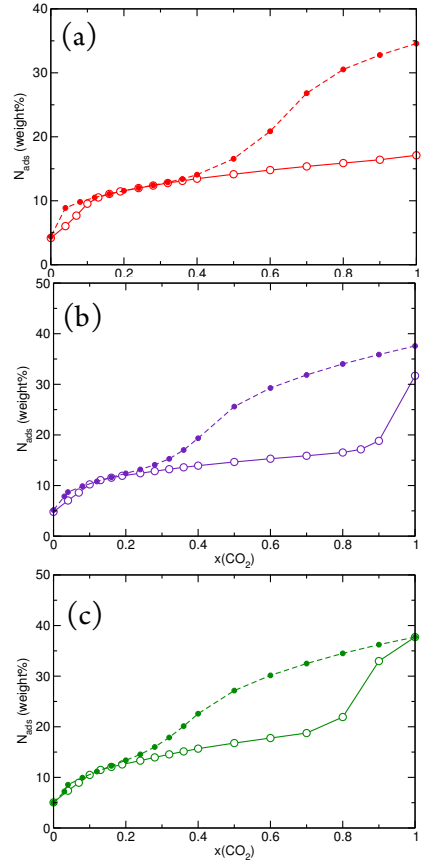

Figure 2. Experimental uptake and release isobars-isotherms of a mixture of $\mathrm{CO}_{2}$ and $\mathrm{CH}_{4}$ in MIL-53( $\left.\mathrm{Al}\right)$, as a function $\mathrm{CO}_{2}$ molar fraction, at $273 \mathrm{~K}$. (a) $P=2.75 \mathrm{bar}$; (b) $P=3.5 \mathrm{bar}$; (c) $P=4$ bar.

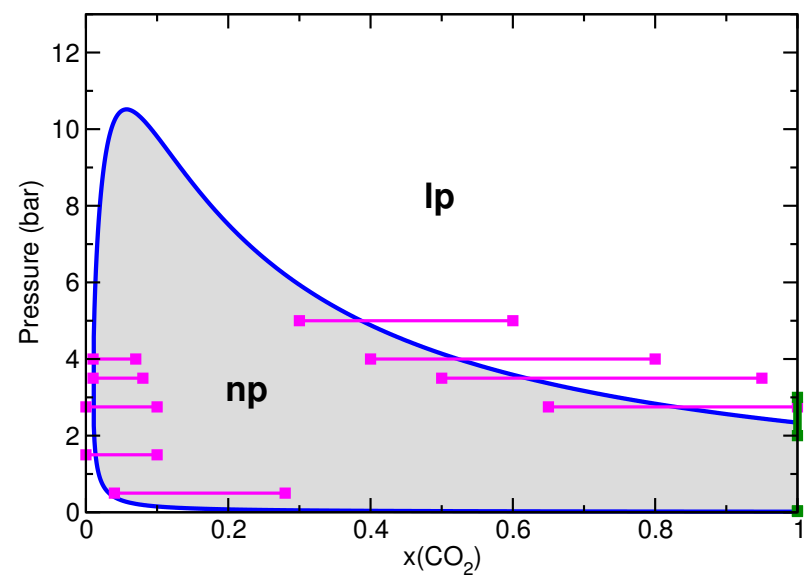

Figure 3. Pressure-composition phase diagram for MIL-53(Al) with a $\mathrm{CO}_{2} / \mathrm{CH}_{4}$ mixture at $273 \mathrm{~K}$, indicating the region of stability of the $\mathrm{np}$ phase (in gray) and lp phase (in white). Experimental pressures for structure transitions are in magenta (width corresponds to the experimental hysteresis loop). Green vertical ranges indicate the purecomponent transition pressure.$^{17}$ The theoretical diagram predicted by the OFAST model is reported as the blue line.
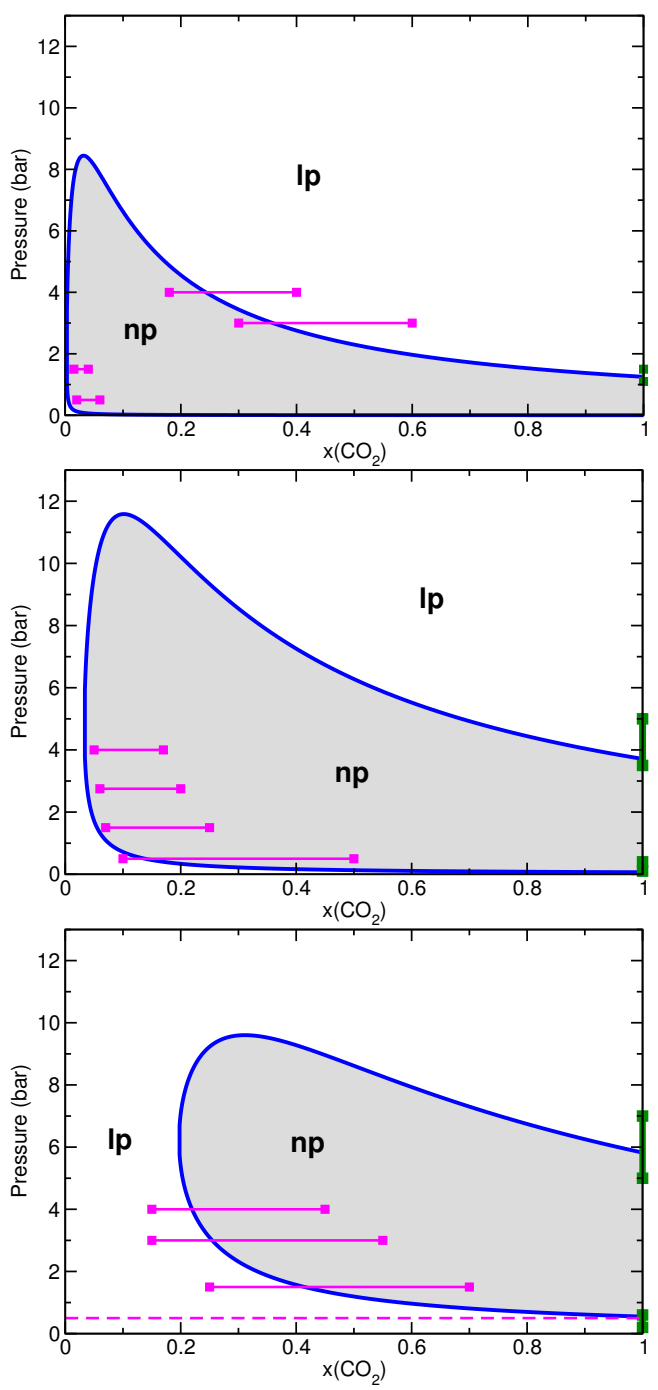

Figure 4. Pressure-composition coadsorption phase diagram for a $\mathrm{CO}_{2} / \mathrm{CH}_{4}$ mixture at 253,292 , and $323 \mathrm{~K}$ in MIL-53(Al). See caption of Fig. 3 for the color code. 


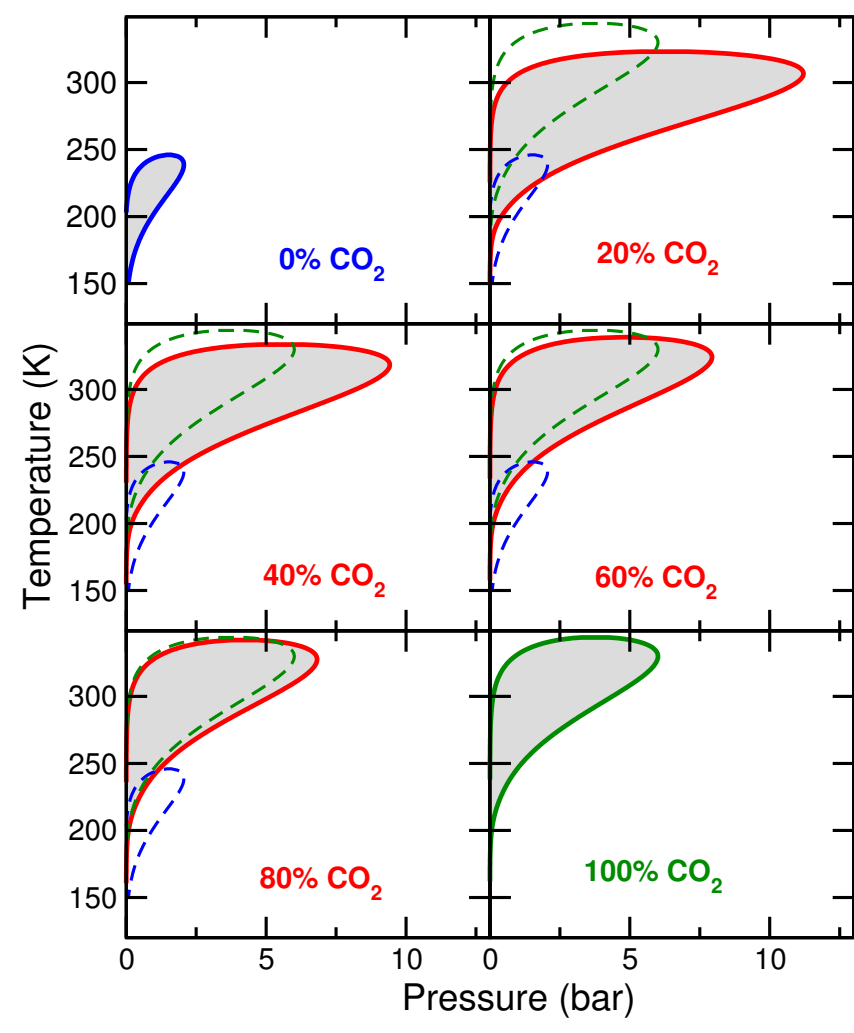

Figure 5. Temperature-pressure phase diagram of MIL-53(Al) upon adsorption of a $\mathrm{CO}_{2} / \mathrm{CH}_{4}$ mixture, with increasing $\mathrm{CO}_{2}$ molar fraction. Dashed lines correspond to pure component diagrams.

\section{ASSOCIATED CONTENT}

Supporting Information. Figures of the $\mathrm{lp}$ and np structures of MIL53(Al), coadsorption isobars-isotherms and full set of model parameters. This information is available free of charge via the Internet at http://pubs.acs.org.

\section{AUTHOR INFORMATION}

\section{Corresponding Author}

*fx.coudert@chimie-paristech.fr

\section{Funding Sources}

This work was partly funded by the Agence Nationale de la Recherche project SOFT-CRYSTAB (ANR-2010-BLAN-0822).
The authors thank Dr. Andrei Nossov for expert technical assistance. Dr. T. Loiseau and professor G. Férey are gratefully acknowledged for providing us with the MIL-53(Al) sample.

\section{REFERENCES}

(1) Rowsell, L. C.; Yaghi, O. M. Micro. Meso. Mater. 2004, 73, 3.

(2) Kitagawa, S.; Kitaura, R.; Noro, S. Angew. Chem. 2004, 43, 2334.

(3) Themed issue: metal organic frameworks, Chem. Soc. Rev. 2009, 38, 1201.

(4) Farrusseng, D.; Aguado, S.; Pinel, C. Angew. Chem. 2009, 48, 7502.

(5) Ma, S. Pure Appl. Chem. 2009, 81, 2235-2251.

(6) Krishna, R.; Long, J. R. J. Phys. Chem. C 2011 , 115, 12941.

(7) Horike, S. ; Shimomura, S. ; Kitagawa, S. Nat. Chem. 2009, 1, 695.

(8) Liu, Y.; Her, J.-H.; Dailly, A.; Ramirez-Cuesta, A. J.; Neumann, D. A.; Brown, C. M. J. Am. Chem. Soc. 2008, 130, 11813.

(9) Beurroies, I.; Boulhout, M.; Llewellyn, P. L.; Kuchta, B.; Férey, G.; Serre, C.; Denoyel, R. Angew. Chem., Int. Ed. 2010, 49, 7526.

(10) Férey, G.; Serre, C. Chem. Soc. Rev. 2009, 38, 1380.

(11) Kitaura, R.; Seki, K.; Akiyama, G.; Kitagawa, S. Angew. Chem., Int. Ed. 2003, 42, 428.

(12) Finsy, V.; Ma, L.; Alaerts, L.; De Vos, D. E.; Baron, G. V.; Denayer, J. F. M. Microporous Mesoporous Mater. 2009, 120, 221.

(13) Couck, S.; Denayer, J. F. M.; Baron, G. V.; Remy, T.; Gascon, J.; Kapteijn, F. J. Am. Chem. Soc. 2009, 131, 6326.

(14) Hamon, L.; Llewellyn, P. L.; Devic, T.; Ghoufi, A.; Clet, G.; Guillerm, V.; Pirngruber, G. D.; Maurin, G.; Serre, C.; Driver, G.; van Beek, W.; Jolimaitre, E.; Vimont, A.; Daturi M.; Férey, G. J. Am. Chem. Soc. 2009, 131,17490 .

(15) Stavitski, E.; Pidko, E. A.; Couck, S.; Remy, T.; Hensen, E. J. M.; Weckhuysen, B. M.; Denayer, J.; Gascon, J.; Kapteijn, F. Langmuir 2011, 27,3970 .

(16) Coudert, F.-X.; Mellot-Draznieks, C.; Fuchs, A. H.; Boutin, A. J. Am. Chem. Soc. 2009, 131, 11329.

(17) Boutin, A.; Coudert, F.-X.; Springuel-Huet, M.-A.; Neimark, A. V.; Férey, G.; Fuchs, A. H. J. Phys. Chem. C 2010, 114, 22237.

(18) Myers, A. L.; Prausnitz, J. M. AIChE J. 1965, 11,121.

(19) Coudert, F.-X.; Boutin, A.; Jeffroy, M.; Mellot-Draznieks, C.; Fuchs, A. H. Chem. Phys. Chem. 2011, 12, 247.

(20) Jeffroy, M.; Fuchs, A. H.; Boutin, A. Chem. Commun. 2008, 3275.

(21) Coudert, F.-X.; Jeffroy, M.; Fuchs, A. H.; Boutin, A.; MellotDraznieks, C. J. Am. Chem. Soc. 2008, 130, 14294.

(22) Coudert, F.-X. Phys. Chem. Chem. Phys. 2010, 12, 10904.

(23) Boutin, A.; Springuel-Huet, M.-A.; Nossov, A.; Gédéon, A.; Loiseau, T.; Volkringer, C.; Férey, G.; Coudert, F.-X.; Fuchs, A. H. Angew. Chem., Int. Ed. 2009, 48, 8314.

(24) Serre, C.; Bourrelly, S.; Vimont, A.; Ramsahye, N. A.; Maurin, G.; Llewellyn, P. L.; Daturi, M.; Filinchuk, Y.; Leynaud, O.; Barnes, P.; Férey, G. Adv. Mater. 2007, 19, 2246.

\section{ACKNOWLEDGMENT}


Table of Contents Graphic

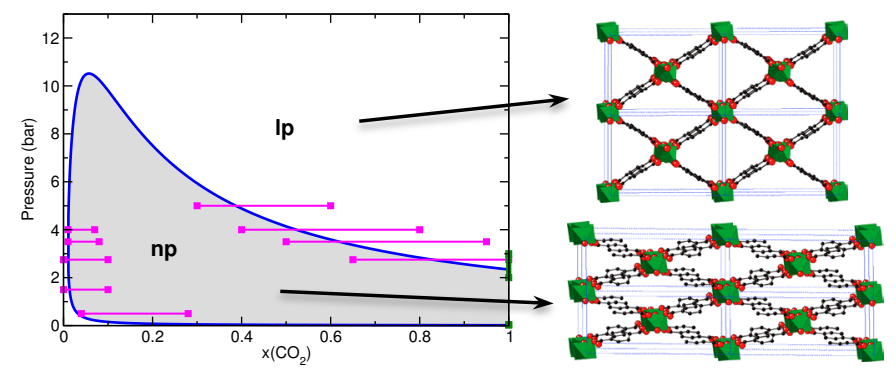

